\section{Research Square}

Preprints are preliminary reports that have not undergone peer review.

They should not be considered conclusive, used to inform clinical practice, or referenced by the media as validated information.

\title{
Understanding What Influences Community-Based Care Coordination Improvement: Interpreting Variation in a Medicare Hospital Readmissions Reduction Program Using the Consolidated Framework for Implementation Research (CFIR)
}

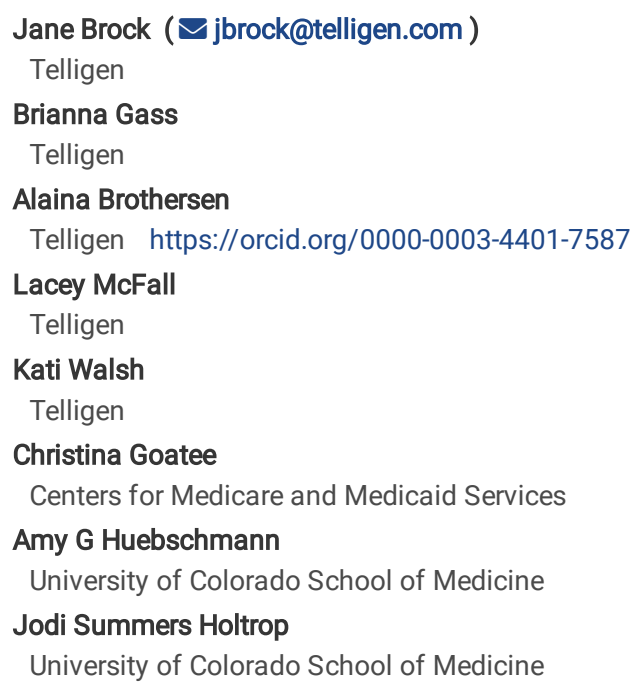




\section{Abstract}

Background Quality Improvement Networks Quality Improvement Organizations (QIN-QIOs) developed community coalitions to align care coordination efforts for Medicare beneficiaries in order to reduce readmission rates within geographically defined communities. This CMS (Centers for Medicare \& Medicaid Services) funded national quality improvement program worked with 380 coalitions from 2014-2019, facilitating a variety of interventions within each community. Baseline readmission rates among communities, calculated from claims data, varied from 17.7 to 112 readmissions/1000 beneficiaries. Program results ranged from $+40.7 \%$ (high performance) to $-35.8 \%$ (low performance) relative improvement.

We applied an implementation framework (CFIR) to the QIN-QIO efforts to define common characteristics of interventions, implementation strategies, and contexts in which improvement efforts took place. We identify features associated with successful and unsuccessful intervention implementation, and with changes in readmission rates.

Methods We selected 22 communities representing a range of relative improvement, geographic characteristics and baseline readmissions rates. We measured the QIN-QIO's perception of influence of individual CFIR constructs on community readmission rates over time using a written assessment and elicited details and mechanisms through structured interviews. Two independent reviewers qualitatively coded transcribed interviews. Final ratings for the influence of each CFIR construct on community performance were assigned by consensus, ranging from -2 (strong negative influence) to +2 (strong positive influence).

Results Some adaptation of the CFIR, such including codes in a coalition domain, and adding constructs to the outer setting domain, such as healthcare market characteristics, helped fit the framework to the QIN-QIO work. The characteristics of individuals domain was less applicable to this study. Several constructs were found to be associated with improvement, or lack of, in readmission rates in communities.

Conclusions The CFIR is an appropriate taxonomy for understanding implementation of care coordination interventions in the QIN-QIO communities, with constructs from the Outer Setting and Process domains having the most influence on successful implementation. Communities effectively reducing readmissions had coalitions with favorable implementation climates, robust stakeholder engagement strategies, and interventions aligned with local concerns and capabilities. The CFIR can help guide, monitor and evaluate community-based improvement initiatives, although further development some constructs is needed.

\section{Contributions To Literature}

- National healthcare quality improvement programs require flexible methods, adaptable interventions, and strategies that can be tailored to unique contexts and populations.

- Quality improvement practitioners recognize the need to elevate the relevance and value of their efforts by generating systematic evidence that might promote rigor, and evaluation and replication using implementation research designs, but methods for identifying the elements necessary for success are not established.

- Our findings suggest that application of an implementation framework to a nationally scaled, complex quality improvement initiative is feasible and appropriate.

- Features of the health care market environment influence the capability of community-based efforts to improve care transitions and reduce hospital readmissions.

\section{Background}

Despite a national priority focus on improving care coordination (1), patients and caregivers still encounter fragmented and disorganized care when moving between health care settings (2). Readmissions are one potential outcome of poor care coordination, or care transition, after hospital discharge (3) (4), and readmissions within 30 days of hospital discharge can be reduced through established evidence-based interventions (5) (6). Even with a set of known, evidence-based interventions, improving care transitions quality has remained a challenge, due to the complexity of implementing these interventions across healthcare settings (7). Care transitions improvement is inevitably a multi-stakeholder undertaking since it relies on activities of inpatient care teams, outpatient or other post-acute setting care teams, patients themselves, and potentially community service providers and informal caregivers (8) (9) (10).

The Centers for Medicare and Medicaid Services (CMS) consider care coordination a strategic priority. CMS has contracted with Quality Improvement Organizations (QIOs) since 2008 to provide technical assistance to multi-stakeholder community coalitions, aiming to promote and align care transitions activities to reduce hospital readmissions (11) (12). The Quality Innovation Network - Quality Improvement Organization (QIN-QIO) program is a large national program administered by CMS to improve health care quality for Medicare beneficiaries (13). Driving improvement through coalitions acknowledges the interdependent nature of care transitions quality, has been referenced as a promising approach by the National Quality Strategy (NQS) (14), and has been successful within the QIO program (15).

QIN-QIOs worked with more than 380 community coalitions between 2014 and 2019; these coalitions performed root cause analyses of hospital readmissions and facilitated implementation of interventions within each community. Most QIN-QIOs also supplied direct technical assistance, such as data collection, analysis, or training in intervention or quality improvement strategies, to individual providers or organizations as possible given the scale of the project. QINQIOs and provider participants tracked and reported process and intermediate outcome measures; by design, these measures were not standardized to encourage customized and adaptable approaches as needed. QIN-QIOs submitted quarterly narrative progress reports describing successes, challenges, and harm mitigation strategies. 
Program progress was tracked by quarterly readmission rates for the Fee-for-Service (FFS) Medicare beneficiaries in each community (readmissions/1000 beneficiaries), calculated from claims data. Readmissions results varied widely among the participating communities, from a $35.0 \%$ reduction from baseline to a $44.2 \%$ increase over the course of the SoW.

Despite robust data and reporting requirements, a large number of participating communities, and variability in outcomes performance it is unclear what interventions and implementation strategies were effective, and in what context. The QIN-QIO program allowed communities maximum flexibility, resulting in wide variation in multiple aspects of individual projects. These included the characteristics of communities and providers engaged in the work, interventions selected, measures collected, populations targeted by efforts, and state and local policy infrastructure. This variation has made it difficult to distill a set of common lessons that might guide future work in care coordination.

We sought to define the implementation characteristics of individual community efforts, and aggregate insights, by applying the Consolidated Framework for Implementation Research (CFIR) (16). The CFIR consolidates a menu of constructs, or characteristics that influence an implementation effort, from multiple theoretical implementation frameworks, organized within five domains. Domains include the organizational setting in which implementation efforts occur (Inner Setting), the external environment beyond the influence of the people engaged in implementation (Outer Setting), features of the intervention itself (Intervention Characteristics), the individuals working to implement an intervention, including the participants in the intervention (Characteristics of Individuals), and the processes used to put an intervention into practice and adapt as necessary (Process). We selected the CFIR because it accounts for Inner and Outer Setting contexts, has readily available support tools (17), and has been used to evaluate complex, large-scale, publicly funded improvement efforts across a variety of settings (18) (19) (20). The purpose of this project was to determine whether the CFIR could serve as an appropriate taxonomy for describing QIN-QIO care coordination efforts, identify CFIR constructs associated with intervention implementation, and associate community characteristics with changes in 30-day hospital readmissions.

\section{Methods}

\section{Theoretical Qualitative Approach:}

We chose a realist evaluation approach to understand factors influencing intervention implementation, and by extension, success or lack of success in achieving desired outcomes. Realist evaluation acknowledges that programs are self-transformational, embedded within dynamic social, political, and environmental systems (21), and best understood through accounting for contextual influence. We used pre-determined constructs from the CFIR supplemenTheoretical Qualitative Approach:ted by inductive coding to create a menu of constructs that could incorporate multiple theories of behavioral change. Inductive determination of constructs allows theory application efforts to be tailored to the specifics of the situation being evaluated, and better reflects the realist philosophies than one individual theory of change (22).

\section{Sample Selection:}

We sorted communities by relative improvement rate (RIR) in readmissions per 1,000 Medicare FFS beneficiaries between two annual timeframes, from baseline (7/1/2013-6/30/2014) to remeasurement (7/1/2016-6/30/2017). We identified communities by RIR in the top $10 \%$, the bottom $10 \%$, and the $10 \%$ centered on 'no improvement'. We defined 'no improvement' as $0.00 \%$ RIR. The lowest RIR communities showed increases in readmissions per 1,000 , or negative RIR. We sorted each set of communities by readmission rate at baseline to identify candidate communities within each stratum that started with high vs. low readmission rates. We selected 22 communities aiming for a group that represented geographic distribution, differently sized Medicare FFS populations, and balance between rural and urban settings (Table 1 located in the appendix). 
Table 1

Characteristics of Selected Communities

\begin{tabular}{|c|c|c|c|c|c|c|c|}
\hline \multirow{3}{*}{$\begin{array}{l}\text { De- } \\
\text { identified } \\
\text { Community }\end{array}$} & \multicolumn{3}{|c|}{ Community Characteristics } & \multicolumn{4}{|c|}{ Medicare Fee-for-Service Population Characteristics } \\
\hline & $\begin{array}{l}\text { Number of } \\
\text { Medicare FFS } \\
\text { Beneficiaries }\end{array}$ & $\begin{array}{l}\text { Baseline } \\
\text { Readmissions } \\
\text { Rate }\end{array}$ & $\begin{array}{l}\text { Geographic } \\
\text { Region }\end{array}$ & $\begin{array}{l}\text { Residence in } \\
\text { Rural ZIP code } \\
\text { (\%) }\end{array}$ & $\begin{array}{l}\text { Medicare- } \\
\text { Medicaid } \\
\text { Eligible (\%) }\end{array}$ & $\begin{array}{l}\text { Residence in } \\
\text { Disadvantaged ZIP } \\
\text { Code (\%)* }\end{array}$ & $\begin{array}{l}\text { Readmission Relative } \\
\text { Improvement Rate } \\
\text { (RIR) }\end{array}$ \\
\hline & $\begin{array}{l}\text { (rounded to } \\
\text { nearest } 1,000 \text { ) }\end{array}$ & & & & & & \\
\hline 1 & 62,000 & 28.448 & SW US & 10.8 & 22.6 & 7.4 & $-0.823 \%$ \\
\hline 2 & 41,000 & 69.028 & SE US & 0.0 & 29 & 14.8 & $1.192 \%$ \\
\hline 3 & 5,000 & 25.067 & NE US & 100.0 & 23.7 & 0 & $-0.227 \%$ \\
\hline 4 & 57,000 & 66.671 & SE US & 58.2 & 25.3 & 15.6 & $15.307 \%$ \\
\hline 5 & 52,000 & 111.422 & MW US & 0.0 & 31.6 & 15.5 & $19.918 \%$ \\
\hline 6 & 19,000 & 29.365 & MW US & 100.0 & 11.4 & 7.6 & $-9.957 \%$ \\
\hline 7 & 37,000 & 54.222 & SW US & 4.1 & 18.9 & 17.8 & $-23.564 \%$ \\
\hline 8 & 44,000 & 65.994 & NE US & 2.0 & 19.5 & 3.7 & $13.774 \%$ \\
\hline 9 & 18,000 & 55.152 & MW US & 4.5 & 14.9 & 3.4 & $25.981 \%$ \\
\hline 10 & 16,000 & 21.742 & NW US & 100.0 & 12.2 & 0.8 & $14.272 \%$ \\
\hline 11 & 25,000 & 58.481 & SE US & 48.2 & 22.5 & 26.9 & $-29.044 \%$ \\
\hline 12 & 15,000 & 27.470 & SW US & 12.1 & 13.8 & 0.4 & $-1.340 \%$ \\
\hline 13 & 52,000 & 81.762 & SE US & 0.0 & 22 & 11.7 & $-9.031 \%$ \\
\hline 14 & 120,000 & 66.550 & NE US & 4.2 & 25.2 & 2.7 & $-12.676 \%$ \\
\hline 15 & 85,000 & 82.078 & MW US & 0.1 & 20.7 & 20.7 & $1.051 \%$ \\
\hline 16 & 4,000 & 21.734 & NW US & 100.0 & 11.1 & 5.8 & $-44.184 \%$ \\
\hline 17 & 54,000 & 24.958 & NW US & 37.6 & 16.5 & 2.3 & $-8.867 \%$ \\
\hline 18 & 86,000 & 52.527 & NE US & 2.9 & 15.5 & 0.5 & $0.765 \%$ \\
\hline 19 & 12,000 & 26.101 & $\begin{array}{l}\text { Non- } \\
\text { Contiguous } \\
\text { US }\end{array}$ & 7.2 & 6.1 & 0.3 & $24.302 \%$ \\
\hline 20 & 105,000 & 41.571 & SW US & 5.3 & 9.1 & 7.5 & $17.036 \%$ \\
\hline
\end{tabular}

\section{Study Participants:}

We invited QIN-QIO staff who led work for the care coordination task from each of the 22 representative communities we identified (Table 1 located in the appendix) and $100 \%$ agreed to complete an assessment (Additional file 1) and participate in a semi-structured interview. Participants were invited to an orientation webinar to explain the goals of the project and to provide an introduction to the CFIR, including links to online resources and a sample paper demonstrating use of the CFIR to evaluate a complex initiative (18).

\section{Data Collection:}

QIN-QIOs were asked to select an intervention for the sample community that they believed either had the greatest impact on readmission rates or impacted the greatest number of resident beneficiaries. They were sent a written assessment that asked for a description of that intervention, and a rating of each CFIR construct according to its impact on implementation of the intervention, and on the community's RIR. In addition, they were asked to indicate the degree of confidence in their ratings, as it was unlikely that QIN-QIO staff would always have the information needed to assess each construct. After each assessment, the research team wrote a brief narrative summary of the community and the intervention and implementation strategies, including identified facilitators and barriers. We then performed 90 minute follow up interviews with each QIN-QIO using a standard guide customized according to the results of the written assessment (Additional file 2). We used open ended questions to clarify our initial understanding, and probes to elicit details related to each CFIR construct. Interviews captured background information about the community, selection of the intervention, and how various CFIR constructs impacted the team's ability to implement the intervention as planned and reduce community readmissions incidence. Interviewees were also asked to reflect on elements that influenced the community's readmission rate regardless of implementation success. Interviews were audio-recorded and transcribed.

\section{Coding and Analysis:}


The first transcript was coded by all five coders through open discussion to establish common interpretation of constructs and identify needs for additional or adapted construct definitions. We created three categories for the construct of evidence strength and quality to reflect the methods used in the task: evidence based on traditional experimental research and reported in peer-reviewed literature; degree to which interventions aligned with root cause analyses (RCA) of readmissions for Medicare beneficiaries in the community; and evidence of success using the chosen approach in a different QIN-QIO-facilitated community. Formal experimental research testing intervention techniques for driving readmissions reduction through coalition-facilitated multi-stakeholder approach is sparse (24), and most QIN-QIO experience, although extensive, is unpublished.

Transcripts were then independently coded using Atlas.ti by two of the five team members, using our codebook (Additional file 3 ) modified from the publicly available CFIR codebook. Coding pairs varied for each community to increase consistency in interpretation of codes. We used a consensual qualitative approach which allowed inductive coding as needed; new suggested codes were discussed with the larger team and added to our codebook through agreement. The team met regularly during the coding process to discuss challenges and coding decisions, and to formalize code definitions to improve interrater reliability. Key decisions were recorded in an audit document for reference.

After coding the first few interviews, all coding teams noted two significant challenges related to accurate assessment of setting. First, assigning structures, processes and implementation elements associated with the coalition to either the inner or outer setting resulted in frequent disagreement and inconsistency, as the coalition was neither the primary setting where most implementation activity occurred (inner setting) nor a setting characterized by elements outside of the control of participants engaged in implementation activities (outer setting). Thus, the team unanimously agreed to establish a coalition domain and allowed any relevant construct to be applied to this domain. (Additional file 3)

Second, given the nature of the work as a community-wide initiative, interviewees often commented on the influence of community-specific elements that did not fit neatly into any of the four outer setting constructs. This was especially apparent in reflections on community readmission rate influences, such as statements noting antagonism between competing hospital systems resulting in insufficient spread of interventions successfully implemented within one system. Coders attributed poorly fitted elements to a broad construct of community characteristics. After coding all transcripts, community characteristics was the most frequently coded construct, often double coded to other outer setting constructs. We aggregated all quotes attributed to the constructs of needs and resources of those served by the organization, external policy and incentives, and community characteristics, recoded them inductively, then established an expanded set of outer setting constructs through consensus. Examples of quotes recoded to new outer setting constructs are included in Table 2 in the appendix. These new constructs were double coded with the original constructs, and not treated as subconstructs or replacements of the original constructs. 


\section{New Construct Example Quotations}

Healthcare

Market

Characteristics

Characteristics

\section{Population}

"The CEOs and the corporations that own the hospitals, they're heads in the bed. You know the type that still have that old school culture in their walls and this comes from the top down, that comes from the CEOs that comes from the corporations. I think that we are late adopters in this area, and we realized that because we see the program, they're across the country and the one key feature for success in some of these programs is that it comes from CEOs that make this a priority. It comes from C-suite to make readmissions a priority and we just don't see that here." Community 7

"And also, too, what we were finding out was that the primary care physicians, some of the major ones were not accepting Medicare patients, new Medicare patients. And then, one of the problems in the coalition that we really had faced and work on was that of the physicians that were taking Medicare patients, none of them were taking call, so it ended up, I mean it was just...and then with the economic downturn they lost their mental health stuff, all their mental health." Community 16

"Many of the hospitals with this zip code fall into what they call safety-net hospitals. And I believe this was the time period where there was so many issues with funding and whether or not hospitals were going to be shut down. One hospital in particular, that is a part of the community, had intense turnover. So, I think that those represent some of the barriers." Community 5
"This is a very rural community - It has struggled with many things in terms of food insecurity, housing, income, opioids. And in probably the first year of our contract, this was the community that actually led the way to be an accountable community for healthcare. So, their community team sort of changed their focus from admissions and re-admissions to addressing what they felt might be preventable issues in terms of keeping people from the ED, but addressing population health." Community 3

"One of the things that they looked at when they first started talking about education or patient education or, I'm sorry, when they work through the root cause analysis what they came up with is that patients not understanding the diagnoses and what they need to do. It came down to do a health literacy issue. The health literacy issue is what turned into - what can we do differently in education if there's this health literacy barrier because of the larger community." Community 5

"Safety net hospitals in [this community] receive a lot of gunshot victims and so then there's security, and there's lots of turnover. The violence in [this community] makes an impact as a competing priority/distraction from the readmissions for the Medicare population." Community 5

"We originally just envisioned it with a nurse and the community health worker and the patient and the iPad. But we quickly learned the importance of, in particular, pharmacy. Pharmacy because these patients are on multiple medications and have multiple chronic conditions and have been in and out of the emergency room and the hospital, so we've had multiple sets of prescriptions written and rewritten for them. So doing med reconciliation-med education of the patient. Frequently, these patients are financially strapped and so making decisions between medication, their rent or their mortgage, or food is what's occurring for them on a regular basis." Community 10

Medical and

Health

Support

Payment

Environment
"We did have success in [this state] to get our state Medicaid program [name] they have recognized the benefits of this, and they now will allow them to bill the [state Medicaid] program for some services. So they're able to recoup some dollars from that. But that's just a recent development and that is just kind of still emerging to see how that will work in the long-term for a funding source." Community 20

"But because they've made access to accountable healthcare, everybody's uninsured rates went down when all that happened. So they're not the poster child in terms of admissions, re-admissions and that sort of work but they are sort of the poster child for understanding what makes their community tick, which is all the communities now in [this state] are trying to do that and head that way." Community 3

"You know I guess one thing about this is the CPC Plus. I don't know if you guys are familiar with that. Because that's just perfectly aligned with ACO work and with care coordination work. And [this area] happens to have been one of the markets that was selected in the original $\mathrm{CPCl}$ demonstration. so there's experience with it there. And then continuing on now with the CPC+. So their primary care providers are paid extra per visit to provide these wrap around services." Community 8
General

Population

Culture

Community

Resource Infrastructure
"I would say that the most successful engagement and re-engagement strategies are all personal relationship based, and that goes back to [this community] being kind of a bounded, smaller, closer-knit community than some other communities that we've worked with. If you know people and you see them in other settings, your ability to guilt them into coming back when they know they already should be coming back is easier when you see them because there are a lot of coalitions in [this community] and other committees, so if you're able to see those people that you're trying to re-engage in other settings, it's a bit easier to get them if you've got other opportunities and your relationship goes beyond just the one coalition setting." Community 9

"...particularly around behavioral health, it was sometimes hard to find the right person to get to, and finding availability, especially when some of these patients were homeless, trying to coordinate how to get the patient connected to those resources." Community 10

"I know they approach their county leaders to address, also their city council to figure out a way of how they can expand some of the transportation. So that would be to look at the bus systems, also any type of taxi services. So there was some limitations that existed. But they were moving forward on trying to figure out how can we expand some of the bus systems for the county area?" Community 12

"...and so with this healthcare system, they now have in place a community health program. I might be wording it wrong, but within this community health program, they're now partnering with some of the food storage places, also with transportation folks. And then also with other programs that are available for patients, so that way when a patient gets referred to that community health program, they can work with the case managers and the patients to find out how they can meet those needs, within a certain geographical area." Community 1

\section{Data Analysis:}

Coder pairs, after agreeing on codes, used a process of data transformation to assign ratings for the influence of each construct on intervention implementation through discussion guided by the CFIR rating rules. All text assigned to a particular code was reviewed by each member of the pair to assign preliminary ratings. The pair then met to reconcile any differences and agree on final ratings. Ratings ranged from -2 (strong negative influence) to +2 (strong positive influence), and were not assigned by comparing communities, but by considering the relative influence of each construct compared to other constructs scored for that community. Constructs were rated 'mixed' if the construct had both positive and negative influences in relative balance; ' 0 ' if the construct was present but did not influence implementation; or 'not rated' if the QIN indicated that it was not present or not sufficiently known to determine influence on implementation. We excluded two communities from further analysis because interviews did not elicit ratable descriptors of interventions, nor allow reliable assessment of coalition functions separable from provider efforts. Ratings were documented for each remaining community $(n=20)$, along with 
a brief rationale for each rating. Once the rating process was complete, the larger team reviewed all ratings and rationales for the entire group of communities in open discussion to ensure consistency and agreement. Rationales were revised as needed for accuracy and clarity.

We used a convergent mixed method design by summarizing our transformed qualitative data with the RIR quantitative data in a matrix (Table 3 located in the appendix and additional file 4). The matrix included all constructs, ratings and rationales for each community, with color coded ratings sorted by RIR performance for visual assessment of associations between RIR and the number of positive and/or negative influencing CFIR constructs. To create a parsimonious set of constructs most relevant to the work, we elected to remove constructs that were rated for less than $40 \%$ of communities ( $8 / 20)$. We assigned the most extreme rating for any subconstruct to the main construct and used expert consensus to balance mixed ratings for multiple subconstructs for communities where this occurred. We retained any subconstructs, as well as added constructs, regardless of why or when they were added that were rated for at least $40 \%$ of communities (Table 4 located in the appendix). 
Table 3

Community Heatmap of Construct Influence

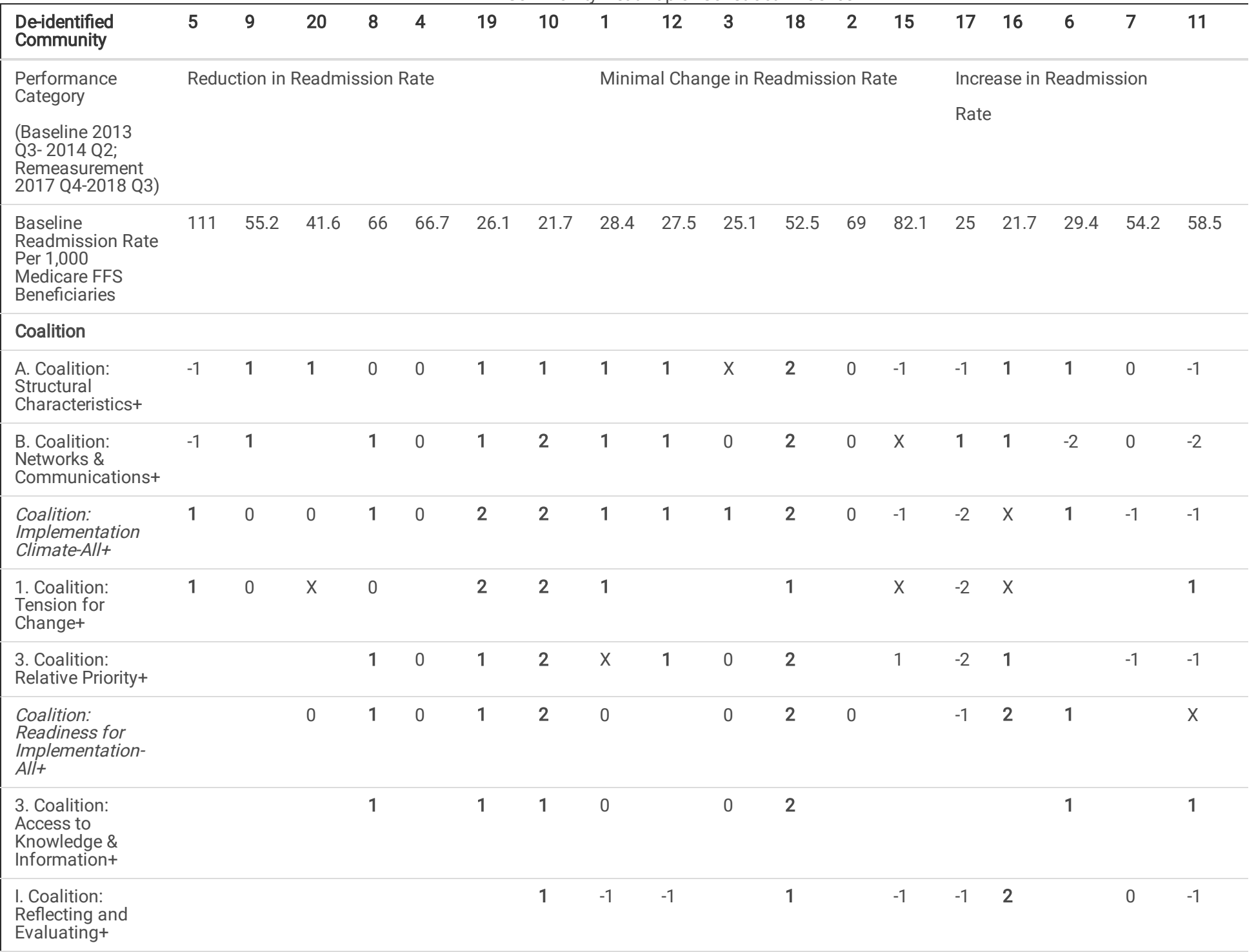

\section{Intervention Characteristics}

\begin{tabular}{|c|c|c|c|c|c|c|c|c|c|c|c|c|c|c|c|c|c|c|}
\hline $\begin{array}{l}\text { A. Intervention } \\
\text { Source }\end{array}$ & & 0 & & 1 & & 2 & & & & 1 & 1 & & & -1 & 1 & 2 & 1 & \\
\hline $\begin{array}{l}\text { B.1 Evidence } \\
\text { Strength \& } \\
\text { Quality: Root } \\
\text { Cause Analysis* }\end{array}$ & 1 & 1 & & 2 & 2 & 1 & 1 & & & 1 & 2 & & 2 & & 2 & 2 & 2 & -2 \\
\hline $\begin{array}{l}\text { B.2 Evidence } \\
\text { Strength \& } \\
\text { Quality: Literature } \\
\text { Evidence* }\end{array}$ & & 1 & & & 1 & 1 & 0 & 2 & & & & 2 & 2 & & & 0 & & \\
\hline $\begin{array}{l}\text { B.3 Evidence } \\
\text { Strength \& } \\
\text { Quality: Success } \\
\text { in Another } \\
\text { Setting* }\end{array}$ & & & 1 & & & 2 & 1 & & 1 & 1 & 1 & & & & & 2 & 1 & 2 \\
\hline $\begin{array}{l}\text { C. Relative } \\
\text { Advantage }\end{array}$ & 2 & & & & 2 & 0 & & 1 & & 2 & 1 & & & $x$ & & 1 & & -1 \\
\hline D. Adaptability & 2 & & 2 & & 1 & 2 & 2 & $x$ & 1 & 2 & 1 & & -1 & 2 & $x$ & 2 & & $x$ \\
\hline E. Trialability & & & & & & & & 1 & 1 & & & & 0 & 2 & -1 & 1 & 1 & \\
\hline F. Complexity & & & & & -1 & 0 & & 1 & & & 1 & 1 & & & & 1 & & 2 \\
\hline H. Cost & 0 & & $x$ & 2 & & & $x$ & 1 & & 1 & & 1 & & -1 & & & 2 & 1 \\
\hline
\end{tabular}

Outer Setting 


\begin{tabular}{|c|c|c|c|c|c|c|c|c|c|c|c|c|c|c|c|c|c|c|}
\hline $\begin{array}{l}\text { De-identified } \\
\text { Community }\end{array}$ & 5 & 9 & 20 & 8 & 4 & 19 & 10 & 1 & 12 & 3 & 18 & 2 & 15 & 17 & 16 & 6 & 7 & 11 \\
\hline $\begin{array}{l}\text { A. Needs \& } \\
\text { Resources of } \\
\text { Those Served by } \\
\text { the Organization }\end{array}$ & 1 & 2 & 2 & & & 0 & 2 & 1 & 1 & 2 & 2 & 2 & $x$ & & 1 & 0 & 2 & -2 \\
\hline $\begin{array}{l}\text { B. } \\
\text { Cosmopolitanism }\end{array}$ & & 2 & 2 & 2 & & 2 & 2 & 2 & 2 & 2 & 1 & & & & & 0 & 1 & $x$ \\
\hline C. Peer Pressure & & 0 & & 0 & & & -1 & & & -1 & & & & -2 & & 1 & & \\
\hline $\begin{array}{l}\text { D. External Policy } \\
\text { \& Incentives }\end{array}$ & -1 & $x$ & 1 & 2 & 1 & & 2 & & & 1 & $x$ & 1 & -2 & -1 & 1 & 2 & 0 & \\
\hline $\begin{array}{l}\text { E. Community } \\
\text { Characteristics* }\end{array}$ & -2 & 1 & & 2 & 1 & 1 & $x$ & 1 & -1 & 2 & $x$ & -1 & $x$ & $x$ & $x$ & -2 & -2 & -2 \\
\hline $\begin{array}{l}\text { F. Population } \\
\text { Characteristics* }\end{array}$ & 2 & 1 & 1 & 0 & & & 2 & & & 1 & $x$ & 0 & 2 & 0 & -1 & & 1 & 0 \\
\hline $\begin{array}{l}\text { G. Healthcare } \\
\text { Market } \\
\text { Characteristics* }\end{array}$ & -2 & 2 & 1 & $x$ & -1 & 1 & 1 & 0 & 0 & 1 & $x$ & -1 & -1 & -1 & -2 & 1 & 0 & -2 \\
\hline $\begin{array}{l}\text { I. Community } \\
\text { Resource } \\
\text { Infrastructure* }\end{array}$ & -1 & & 1 & 1 & & & -1 & & 1 & 2 & & & 2 & & -1 & & 2 & \\
\hline $\begin{array}{l}\text { J. Medical and } \\
\text { Health Support } \\
\text { Payment } \\
\text { Environment in } \\
\text { the Community* }\end{array}$ & & $x$ & 2 & 2 & -1 & & $x$ & & 1 & 2 & 1 & 1 & 0 & & 1 & & & \\
\hline \multicolumn{19}{|l|}{ Inner Setting } \\
\hline $\begin{array}{l}\text { A. Structural } \\
\text { Characteristics }\end{array}$ & & 1 & 1 & 1 & & & 0 & & & 2 & & 2 & & 1 & 1 & & & $x$ \\
\hline C. Culture & & 2 & $x$ & 1 & 1 & 0 & & 2 & & 1 & & 2 & & & 1 & & & \\
\hline $\begin{array}{l}\text { Inner Setting } \\
\text { Implementation } \\
\text { Climate- All }\end{array}$ & & 1 & 2 & 2 & 2 & 1 & -1 & 1 & -1 & 2 & & -1 & -1 & 1 & 1 & 2 & 2 & -1 \\
\hline $\begin{array}{l}\text { 1. Tension for } \\
\text { Change }\end{array}$ & & & 1 & 2 & & & & & & 1 & & 1 & 1 & & & 2 & 1 & -1 \\
\hline 2. Compatibility & & & 2 & 2 & & 1 & & 1 & -1 & 2 & & -1 & -2 & 1 & & 2 & 1 & $x$ \\
\hline 3. Relative Priority & & & 1 & & & & & 1 & $\mathrm{x}$ & 1 & & -1 & -1 & 1 & & & & -1 \\
\hline $\begin{array}{l}\text { 6. Learning } \\
\text { Climate }\end{array}$ & & & & & 2 & & & 1 & & & & $x$ & 0 & & 1 & & 1 & -1 \\
\hline $\begin{array}{l}\text { Inner Setting: } \\
\text { Readiness for } \\
\text { Implementation- } \\
\text { All }\end{array}$ & & 2 & 2 & 2 & 1 & 1 & 1 & 1 & 1 & 2 & & 2 & -1 & -1 & 2 & & 2 & 1 \\
\hline $\begin{array}{l}\text { 1. Leadership } \\
\text { Engagement }\end{array}$ & & 2 & 2 & & 2 & & & & 1 & & & & & 2 & & & 2 & -1 \\
\hline $\begin{array}{l}\text { 2. Available } \\
\text { Resources }\end{array}$ & & 2 & 2 & & $x$ & 0 & 1 & 1 & & & & 2 & -1 & & 2 & & 1 & 2 \\
\hline $\begin{array}{l}\text { 3. Access to } \\
\text { Knowledge \& } \\
\text { Information }\end{array}$ & & & 1 & 2 & 0 & & 1 & 1 & & & & & $x$ & -2 & & & & 1 \\
\hline \multicolumn{19}{|c|}{ Characteristics of Individuals } \\
\hline $\begin{array}{l}\text { E. Other Personal } \\
\text { Attributes }\end{array}$ & & & 2 & & 1 & 2 & 1 & & & 2 & & $x$ & 1 & 1 & & $x$ & 2 & 1 \\
\hline \multicolumn{19}{|l|}{ Process } \\
\hline A. Planning & & & & & 0 & 1 & 1 & -1 & -2 & 2 & & & -2 & -2 & 2 & 2 & 1 & -2 \\
\hline $\begin{array}{l}\text { Process: } \\
\text { Engaging-All }\end{array}$ & & 2 & 1 & & 2 & 2 & 2 & $x$ & -1 & 2 & 2 & 1 & -1 & -2 & 2 & 1 & 2 & -2 \\
\hline $\begin{array}{l}\text { 1. Opinion } \\
\text { Leaders }\end{array}$ & & & 1 & & 2 & 1 & & & & 2 & & & 1 & & 1 & $x$ & 2 & -1 \\
\hline 3. Champions & & 2 & $x$ & & 2 & & 1 & 1 & 1 & 2 & & 2 & -1 & & 2 & & & 1 \\
\hline
\end{tabular}




\begin{tabular}{|c|c|c|c|c|c|c|c|c|c|c|c|c|c|c|c|c|c|c|}
\hline $\begin{array}{l}\text { De-identified } \\
\text { Community }\end{array}$ & 5 & 9 & 20 & 8 & 4 & 19 & 10 & 1 & 12 & 3 & 18 & 2 & 15 & 17 & 16 & 6 & 7 & 11 \\
\hline $\begin{array}{l}\text { 4. External } \\
\text { Change Agents }\end{array}$ & & 1 & & & & & & -2 & 1 & & & & 1 & -1 & & 1 & $x$ & -2 \\
\hline $\begin{array}{l}\text { 5. Key } \\
\text { Stakeholders }\end{array}$ & & & -1 & & & 2 & 2 & 2 & -2 & 2 & 1 & -1 & -2 & -1 & 2 & & 2 & \\
\hline $\begin{array}{l}\text { 6. Intervention } \\
\text { Participants }\end{array}$ & & 2 & 1 & & & 2 & & $x$ & & 1 & 1 & 2 & -2 & 1 & & 0 & 1 & -1 \\
\hline C. Executing & -1 & & & & $x$ & 2 & 1 & -2 & -2 & 1 & & $x$ & -1 & -1 & & 1 & 1 & -2 \\
\hline $\begin{array}{l}\text { D. Reflecting \& } \\
\text { Evaluating }\end{array}$ & 1 & 2 & 1 & & 1 & & & $x$ & -2 & 2 & -1 & 1 & & & 1 & & 1 & -2 \\
\hline \multicolumn{19}{|c|}{$-2=$ Strong negative influence on implementation } \\
\hline \multicolumn{19}{|c|}{$-1=$ Weak negative influence on implementation } \\
\hline \multicolumn{19}{|c|}{$0=$ No influence on implementation } \\
\hline \multicolumn{19}{|c|}{$\mathrm{X}=$ Mixed influence on implementation } \\
\hline \multicolumn{19}{|c|}{1 = Weak positive influence on implementation } \\
\hline \multicolumn{19}{|c|}{$2=$ Strong positive influence on implementation } \\
\hline \multicolumn{19}{|c|}{ Blank = not enough information to rate } \\
\hline \multicolumn{19}{|c|}{ + Existing CFIR constructs coded to coalition setting } \\
\hline *New construct & P & $y$ & & & & & & & & & & & & & & & & \\
\hline
\end{tabular}


Table 4

Construct Presence from Highest to Lowest

\begin{tabular}{|c|c|c|c|c|c|}
\hline \multirow[b]{2}{*}{ CFIR Construct } & \multicolumn{5}{|c|}{ Performance Category } \\
\hline & $\begin{array}{l}\text { Reduction in } \\
\text { Readmission Rates }\end{array}$ & $\begin{array}{l}\text { Minimal Change in } \\
\text { Readmission Rates }\end{array}$ & $\begin{array}{l}\text { Increase in } \\
\text { Readmission Rates }\end{array}$ & Total & Possible \\
\hline Coalition: Structural Characteristics+ & $7 / 7$ & $6 / 6$ & $7 / 7$ & 20 & 20 \\
\hline Coalition: Implementation Climate (all)+ & $7 / 7$ & $6 / 6$ & $7 / 7$ & 20 & 20 \\
\hline Outer Setting: Healthcare Market Characteristics* & $7 / 7$ & $6 / 6$ & $7 / 7$ & 20 & 20 \\
\hline Outer Setting: Community Characteristics* & $6 / 7$ & $6 / 6$ & $7 / 7$ & 19 & 20 \\
\hline Coalition: Networks \& Communications+ & $6 / 7$ & $6 / 6$ & $6 / 7$ & 18 & 20 \\
\hline Inner Setting: Implementation Climate (all) & $6 / 7$ & $5 / 6$ & $7 / 7$ & 18 & 20 \\
\hline Process: Engaging (all) & $5 / 7$ & $6 / 6$ & $7 / 7$ & 18 & 20 \\
\hline $\begin{array}{l}\text { Outer Setting: Needs \& Resources of Those Served by } \\
\text { the Organization }\end{array}$ & $5 / 7$ & $6 / 6$ & $6 / 7$ & 17 & 20 \\
\hline Inner Setting: Readiness for Implementation (all) & $6 / 7$ & $5 / 6$ & $6 / 7$ & 17 & 20 \\
\hline Outer Setting: External Policy \& Incentives & $6 / 7$ & $4 / 6$ & $6 / 7$ & 16 & 20 \\
\hline Intervention Characteristics: Adaptability & $5 / 7$ & $5 / 6$ & $6 / 7$ & 16 & 20 \\
\hline Coalition: Readiness for Implementation (all)+ & $5 / 7$ & $4 / 6$ & $6 / 7$ & 15 & 20 \\
\hline Outer Setting: Population Characteristics* & $5 / 7$ & $4 / 6$ & $6 / 7$ & 15 & 20 \\
\hline $\begin{array}{l}\text { Intervention Characteristics: Evidence Strength \& } \\
\text { Quality-Root Cause Analysis* }\end{array}$ & $6 / 7$ & $3 / 6$ & $6 / 7$ & 15 & 20 \\
\hline Inner Setting: Compatibility & $3 / 7$ & $5 / 6$ & $6 / 7$ & 14 & 20 \\
\hline Process: Executing & $4 / 7$ & $5 / 6$ & $5 / 7$ & 14 & 20 \\
\hline Coalition: Implementation Climate- Relative Priority+ & $4 / 7$ & $5 / 6$ & $4 / 7$ & 13 & 20 \\
\hline Outer Setting: Cosmopolitanism & $5 / 7$ & $4 / 6$ & $4 / 7$ & 13 & 20 \\
\hline $\begin{array}{l}\text { Outer Setting: Medical and Health Support Payment } \\
\text { Environment in the Community* }\end{array}$ & $5 / 7$ & $5 / 6$ & $3 / 7$ & 13 & 20 \\
\hline Process: Planning & $3 / 7$ & $4 / 6$ & $6 / 7$ & 13 & 20 \\
\hline Process: Engaging- Key Stakeholders & $3 / 7$ & $6 / 6$ & $4 / 7$ & 13 & 20 \\
\hline Process: Engaging-Intervention Participants & $3 / 7$ & $5 / 6$ & $5 / 7$ & 13 & 20 \\
\hline $\begin{array}{l}\text { Coalition: Implementation Climate- Tension for } \\
\text { Change+ }\end{array}$ & $6 / 7$ & $3 / 6$ & $3 / 7$ & 12 & 20 \\
\hline $\begin{array}{l}\text { Inner Setting: Readiness for Implementation- Available } \\
\text { Resources }\end{array}$ & $5 / 7$ & $3 / 6$ & $4 / 7$ & 12 & 20 \\
\hline Characteristics of Individuals: Other Personal Attributes & $4 / 7$ & $3 / 6$ & $5 / 7$ & 12 & 20 \\
\hline Process: Engaging- Champions & $4 / 7$ & $5 / 6$ & $3 / 7$ & 12 & 20 \\
\hline Process: Reflecting \& Evaluating & $4 / 7$ & $5 / 6$ & $3 / 7$ & 12 & 20 \\
\hline $\begin{array}{l}\text { Intervention Characteristics: Evidence Strength \& } \\
\text { Quality-Success in Another Setting* }\end{array}$ & $3 / 7$ & $3 / 6$ & $5 / 7$ & 11 & 20 \\
\hline Intervention Characteristics: Relative Advantage & $3 / 7$ & $3 / 6$ & $5 / 7$ & 11 & 20 \\
\hline Intervention Characteristics: Cost & $4 / 7$ & $3 / 6$ & $4 / 7$ & 11 & 20 \\
\hline Inner Setting: Structural Characteristics & $4 / 7$ & $2 / 6$ & $5 / 7$ & 11 & 20 \\
\hline Coalition: Reflecting \& Evaluating+ & $1 / 7$ & $4 / 6$ & $5 / 7$ & 10 & 20 \\
\hline Outer Setting: Community Resource Infrastructure* & $4 / 7$ & $3 / 6$ & $3 / 7$ & 10 & 20 \\
\hline $\begin{array}{l}\text { Inner Setting: Implementation Climate- Tension for } \\
\text { Change }\end{array}$ & $2 / 7$ & $3 / 6$ & $5 / 7$ & 10 & 20 \\
\hline Inner Setting: Implementation Climate- Relative Priority & $1 / 7$ & $5 / 6$ & $4 / 7$ & 10 & 20 \\
\hline $\begin{array}{l}\text { Coalition: Readiness for Implementation- Access to } \\
\text { Knowledge \& Information+ }\end{array}$ & $3 / 7$ & $3 / 6$ & $3 / 7$ & 9 & 20 \\
\hline
\end{tabular}




\begin{tabular}{|c|c|c|c|c|c|}
\hline & Perfo & & & & \\
\hline Intervention Characteristics: Intervention Source & $3 / 7$ & $2 / 6$ & $4 / 7$ & 9 & 20 \\
\hline Inner Setting: Culture & $5 / 7$ & $3 / 6$ & $1 / 7$ & 9 & 20 \\
\hline $\begin{array}{l}\text { Inner Setting: Readiness for Implementation- } \\
\text { Leadership Engagement }\end{array}$ & $3 / 7$ & $1 / 6$ & $5 / 7$ & 9 & 20 \\
\hline $\begin{array}{l}\text { Inner Setting: Readiness for Implementation- Access to } \\
\text { Knowledge \& Information }\end{array}$ & $4 / 7$ & $2 / 6$ & $3 / 7$ & 9 & 20 \\
\hline Process: Engaging- Opinion Leaders & $3 / 7$ & $2 / 6$ & $4 / 7$ & 9 & 20 \\
\hline Process: Engaging- External Change Agents & $1 / 7$ & $3 / 6$ & $5 / 7$ & 9 & 20 \\
\hline $\begin{array}{l}\text { Intervention Characteristics: Evidence Strength \& } \\
\text { Quality- Literature Evidence* }\end{array}$ & $4 / 7$ & $3 / 6$ & $1 / 7$ & 8 & 20 \\
\hline Intervention Characteristics: Trialability & $0 / 7$ & $3 / 6$ & $5 / 7$ & 8 & 20 \\
\hline Intervention Characteristics: Complexity & $2 / 7$ & $3 / 6$ & $3 / 7$ & 8 & 20 \\
\hline Outer Setting: Peer Pressure & $3 / 7$ & $1 / 6$ & $4 / 7$ & 8 & 20 \\
\hline Inner Setting: Learning Climate & $1 / 7$ & $3 / 6$ & $4 / 7$ & 8 & 20 \\
\hline Coalition: Compatibility+ & $2 / 7$ & $3 / 6$ & $2 / 7$ & 7 & 20 \\
\hline $\begin{array}{l}\text { Intervention Characteristics: Design Quality \& } \\
\text { Packaging }\end{array}$ & $1 / 7$ & $2 / 6$ & $4 / 7$ & 7 & 20 \\
\hline Outer Setting: Physical Features of the Community* & $2 / 7$ & $2 / 6$ & $3 / 7$ & 7 & 20 \\
\hline Inner Setting: Networks \& Communications & $2 / 7$ & $2 / 6$ & $3 / 7$ & 7 & 20 \\
\hline $\begin{array}{l}\text { Characteristics of Individuals: Knowledge \& Beliefs } \\
\text { about the Intervention }\end{array}$ & $1 / 7$ & $4 / 6$ & $2 / 7$ & 7 & 20 \\
\hline Coalition: Culture+ & $3 / 7$ & $1 / 6$ & $2 / 7$ & 6 & 20 \\
\hline Coalition Implementation Climate Learning Climate+ & $3 / 7$ & $1 / 6$ & $2 / 7$ & 6 & 20 \\
\hline $\begin{array}{l}\text { Coalition: Readiness for Implementation- Leadership } \\
\text { Engagement+ }\end{array}$ & $3 / 7$ & $0 / 6$ & $3 / 7$ & 6 & 20 \\
\hline $\begin{array}{l}\text { Coalition: Readiness for Implementation- Available } \\
\text { Resources+ }\end{array}$ & $2 / 7$ & $1 / 6$ & $3 / 7$ & 6 & 20 \\
\hline Coalition: Champions+ & $4 / 7$ & $0 / 6$ & $2 / 7$ & 6 & 20 \\
\hline Coalition: Knowledge and Beliefs about the Coalition+ & $1 / 7$ & $1 / 6$ & $4 / 7$ & 6 & 20 \\
\hline $\begin{array}{l}\text { Process: Engaging- Formally Appointed Internal } \\
\text { Implementation Leaders }\end{array}$ & $1 / 7$ & $3 / 6$ & $2 / 7$ & 6 & 20 \\
\hline Coalition: Peer Pressure+ & $3 / 7$ & $1 / 6$ & $1 / 7$ & 5 & 20 \\
\hline $\begin{array}{l}\text { Inner Setting: Implementation Climate- Organizational } \\
\text { Incentives \& Rewards }\end{array}$ & $4 / 7$ & $0 / 6$ & $1 / 7$ & 5 & 20 \\
\hline $\begin{array}{l}\text { Characteristics of Individuals: Individual Identification } \\
\text { with Organization }\end{array}$ & $2 / 7$ & $2 / 6$ & $1 / 7$ & 5 & 20 \\
\hline Outer Setting: Big Events* & $3 / 7$ & $0 / 6$ & $1 / 7$ & 4 & 20 \\
\hline Characteristics of Individuals: Self-Efficacy & $3 / 7$ & $0 / 6$ & $1 / 7$ & 4 & 20 \\
\hline $\begin{array}{l}\text { Coalition: Implementation Climate- Organizational } \\
\text { Incentives \& Rewards+ }\end{array}$ & $1 / 7$ & $1 / 6$ & $1 / 7$ & 3 & 20 \\
\hline Coalition: Goals \& Feedback+ & $2 / 7$ & $0 / 6$ & $1 / 7$ & 3 & 20 \\
\hline Coalition: Individual Identification with Organization+ & $2 / 7$ & $0 / 6$ & $1 / 7$ & 3 & 20 \\
\hline Outer Setting: General Population Culture* & $1 / 7$ & $1 / 6$ & $1 / 7$ & 3 & 20 \\
\hline $\begin{array}{l}\text { Inner Setting: Implementation Climate- Goals \& } \\
\text { Feedback }\end{array}$ & $0 / 7$ & $1 / 6$ & $1 / 7$ & 2 & 20 \\
\hline $\begin{array}{l}\text { Characteristics of Individuals: Individual Stage of } \\
\text { Change }\end{array}$ & $0 / 7$ & $0 / 6$ & $1 / 7$ & 1 & 20 \\
\hline \multicolumn{6}{|l|}{ + Existing CFIR constructs coded to coalition setting } \\
\hline * New construct developed by team & & & & & \\
\hline
\end{tabular}


To further explore the relationship between implementation constructs and RIR performance, we tabulated codes most frequently co-occurring with "explanation of RIR performance."

\section{Results}

\section{CFIR as a taxonomy for describing QIN-QIO efforts to coordinate care}

We found that the CFIR provided an appropriate taxonomy for characterizing the QIN-QIO care coordination efforts and their associated contexts. We note some modifications and additions made to the CFIR to adapt to some of the unique aspects of the QIN-QIO role and the community-based nature of the work. Of the $41 \mathrm{CFIR}$ constructs and subconstructs defined in the online codebook template (25), all were scored for at least one community, and 30 (73\%) were coded and rated in at least eight (40\%) communities. The CFIR framework allows for adaptation in selecting the most applicable domains or constructs for a particular inquiry, or in adding and adjusting constructs as appropriate. After adding coalition constructs, three evidence strength \& quality subconstructs, and seven outer setting codes, our codebook had 70 possible constructs. Of those, 47 were scored in at least eight (40\%) of the 20 communities (table 4 located in the appendix).

The domains that QIN-QIOs found most relevant to their coalition's efforts were outer setting, where all constructs (100\%) were consistently scored, and process, for which nine out of ten (90\%) constructs and subconstructs were scored. Characteristics of individuals was the least applicable domain, with only one construct consistently detected and rated.

The most frequently applied outer setting constructs were external policy and incentives, needs and resources of population served by the organization, and community characteristics. After inductive coding of text originally coded to community characteristics, we found the newly added sub-construct healthcare market characteristics to be applicable to all 20 communities.

Among constructs in the added coalition domain, coalition structure and coalition implementation climate were scored for all communities. QIN-QIOs described many features of coalition structure, such as composition, meeting frequency, maturity, and use of subgroups like workgroups or committees.

Finally, the constructs related to characterizing individuals in the characteristics of individuals domain and the functional roles in the process engaging subconstructs proved challenging for us. Because individuals were engaged to serve roles within a coalition as well as within their inner settings, we were often unclear on how to assign the engagement roles as suggested by the CFIR process subconstructs (e.g., champion versus key stakeholder). In interviews, we heard many compelling stories about a specific person influencing implementation efforts, but there were no consistent elements in the roles those people served within the coalition, their organizations, or the broader community, nor in the activities that they performed. Additionally, QIN-QIOs were seldom able to provide the depth of personal information about these individuals that would be necessary to reliably ascertain characteristics such as stage of change or self-efficacy. We therefore did not further assess constructs within the characteristics of individuals domain and recommend future work to better define important roles for engagement within a multi-provider coalition-facilitated program.

\section{Constructs associated with care coordination intervention implementation}

We found apparent relationships between the influence of certain constructs and performance on RIR. High RIR communities had more constructs rated as positive influences (138/182), as compared to low RIR communities (117/216) and low RIR communities had more constructs rated as negative influences (66/216) compared to high RIR communities (14/182) (table 3 located in the appendix and additional file 4$)$. Of the 70 constructs assessed, 14 distinguished high RIR from low RIR communities.

\section{Coalition Domain:}

The quality of networks and communication was more often negative in low performing communities compared to flat or high performers. One of the most valued aspects of coalitions generally was that they provided a rare opportunity for individuals in similar roles from different organizations (e.g., case managers) to interact, even in communities in which coalition participation did not seemingly facilitate implementation of interventions. Among lower performing communities, there were several examples of coalitions in which attendees remained grouped within their own organizations and interacted very little or shared little information.

The aggregated implementation climate construct and the sub-constructs of tension for change and the perceived relative priority of interventions within the coalition environment were also more likely to be negative in low performers. During interviews, we heard that many stakeholders, despite valuing coalition participation, did not necessarily have a sense of urgency to address readmissions or implement an intervention in their organizations. Reasons cited included low baseline readmissions rates, and/or other population factors being perceived as a higher priority for the community.

The coalition structure construct, despite being one of the most commonly scored constructs, did not distinguish performance. This construct incorporates a variety of characteristics, and it is likely that more detailed subconstructs should be established to tease out influential differences.

\section{Intervention characteristics:}

The constructs within the Intervention Characteristics domain are more likely to be negative for low performing communities compared to others, although this relationship is less evident for the individual constructs.

\section{Inner setting:}


The compatibility construct was less negative among high RIR communities compared to flat or low RIR communities, indicating interventions well aligned with the values and workflows of providers implementing those interventions are more likely to result in lower readmissions.

Similarly, constructs of readiness for implementation were more positive among high RIR communities relative to low and flat RIR communities, indicating that the capability of implementers to influence readiness is an important component for success. The subconstruct of leadership engagement showed the strongest relationship within this construct, indicating that visible commitment and involvement of leadership was a distinguishing element of successful implementation within this project.

\section{Process:}

The engaging construct (including all subconstructs) had more positive ratings among high RIR communities compared to all others. Despite our challenges in assigning roles to those engaged, this provides evidence that an important characteristic of high performers is the capability to get the appropriate people involved in facilitating implementation. Conversely, being unable to engage the appropriate people is a significant barrier to implementation within a setting.

\section{Outer setting:}

The outer setting domain constructs were also rated as negative influences more frequently among low RIR communities, and positive influences among high RIR communities. The construct community characteristics showed the strongest relationship. This code had been added inductively to capture notable features in a community as described in interviews and was rated in all but one of the communities. No low performing community received a positive rating for this construct. The similarly created new construct healthcare market characteristics also showed a strong relationship with RIR performance. Only one low RIR community had a positive rating for this construct, and two high RIR communities rated negatively for this construct. This may indicate that while healthcare market characteristics can be a significant barrier to implementation, it is not necessarily an insurmountable one.

\section{Community characteristics associated with changes in 30-day hospital readmissions}

We tabulated codes that co-occurred with explanation of RIR performance, a code we added to capture response to a specific interview question to elicit perceptions of what most influenced successful reduction of readmissions in each community (table 5 located in the appendix).

Healthcare market characteristics was by far the most frequently co-occurring construct (14/20), and was more often cited by low and stable RIR communities (9 of 13), than high RIR communities (3 of 7). Other outer setting constructs, including population characteristics and physical features of the community also frequently co-occurred with RIR performance, though neither of these showed clear association with performance.

The implementation climate construct within the coalition domain also frequently co-occurred (7) with performance, with more high RIR communities (4) noting this than low performers (2). Inner setting implementation climate was also noted (5), though not as often, and not as strongly associated with community RIR. Example quotes associated with the most frequent co-occurring codes with RIR performance are shown in Table 6 located in the appendix.

Table 5

CFIR Constructs Most Often Associated with Respondents' Explanation of RIR Performance

Performance Category

\begin{tabular}{|c|c|c|c|c|}
\hline & $\begin{array}{l}\text { Reduction in } \\
\text { Readmission } \\
\text { Rates }\end{array}$ & $\begin{array}{l}\text { Minimal Change in } \\
\text { Readmission Rates }\end{array}$ & $\begin{array}{l}\text { Increase in } \\
\text { Readmission } \\
\text { Rates }\end{array}$ & $\begin{array}{l}\text { Total Number of Communities } \\
\text { Reporting this Factor }\end{array}$ \\
\hline $\begin{array}{l}\text { Explanation of RIR Performance- Outer Setting: } \\
\text { Healthcare Market Characteristics }\end{array}$ & 2 & 2 & 6 & 10 \\
\hline $\begin{array}{l}\text { Explanation of RIR performance-Coalition } \\
\text { Implementation Climate (all) }\end{array}$ & 4 & 2 & 1 & 7 \\
\hline $\begin{array}{l}\text { Explanation of RIR performance-Outer Setting: } \\
\text { Population Characteristics }\end{array}$ & 1 & 4 & 1 & 6 \\
\hline $\begin{array}{l}\text { Explanation of RIR performance-Outer Setting: } \\
\text { Physical Features of the Community }\end{array}$ & 2 & 2 & 2 & 6 \\
\hline $\begin{array}{l}\text { Explanation of RIR performance-Inner Setting: } \\
\text { Implementation Climate (all) }\end{array}$ & 2 & 0 & 3 & 5 \\
\hline
\end{tabular}




\begin{tabular}{|c|c|c|}
\hline $\begin{array}{l}\text { Co-occurring } \\
\text { construct }\end{array}$ & $\begin{array}{l}\text { Community } \\
\text { category } \\
\text { (Performance } \\
\text { on RIR) }\end{array}$ & Relevant quote(s) \\
\hline $\begin{array}{l}\text { Outer Setting: } \\
\text { Healthcare } \\
\text { Market } \\
\text { Characteristics }\end{array}$ & $\begin{array}{l}\text { Reduction in } \\
\text { readmission } \\
\text { rates }\end{array}$ & $\begin{array}{l}\text { "The other places the turnovers are just phenomenal. We see that in every setting, especially in a leadership position.... } \\
\text { I think that's a key right there. Is that this hospital, and I will say that other major hospital in that coalition, also is } \\
\text { active in a similar intervention.... You have two rather large hospital systems do something very similar in terms of } \\
\text { follow-up after discharge and I think that had a lot to do. We have a lot of consistency in there in terms of the staff } \\
\text { performing it. Because that's when things tend to fall apart. When somebody leaves and the new person's not aware of } \\
\text { what's going on or comes in and changes things. I think that has a lot to do with it." }\end{array}$ \\
\hline $\begin{array}{l}\text { Outer Setting: } \\
\text { Healthcare } \\
\text { Market } \\
\text { Characteristics }\end{array}$ & $\begin{array}{l}\text { Increase in } \\
\text { readmission } \\
\text { rates }\end{array}$ & $\begin{array}{l}\text { "Well, I think the only thing that really happened during the first part of our scope of work, the economic down turn that } \\
\text { we had in [this state], was, you know, statewide. And so we had a number of open positions, a number of staffing } \\
\text { issues overall... I think that started in the spring of } 2015 \text { and it went on for about a year and a half. The two years } \\
\text { where economically, everything was pretty tough in [this state]. We are bouncing back and everything is fine, but again } \\
\text { I don't wanna look at that as an excuse. That's kind of the boom and bust cycle of [this state] and we kinda look at it } \\
\text { that way, but during the time period everybody was looking at other priorities other than readmissions. Let's put it that } \\
\text { way, so." }\end{array}$ \\
\hline $\begin{array}{l}\text { Outer Setting: } \\
\text { Healthcare } \\
\text { Market } \\
\text { Characteristics }\end{array}$ & $\begin{array}{l}\text { Minimal } \\
\text { change in } \\
\text { readmission } \\
\text { rates }\end{array}$ & $\begin{array}{l}\text { "I think one of the issues what that a high number of our readmitting beneficiaries in this community are in the under } \\
65 \text { community; that is almost } 50 \% \text {. And it is very difficult to get those patients on the radar at the hospital because } \\
\text { they don't have a penalty. I think the expectation in the meantime, there have been several a couple other hospitals } \\
\text { have been bought and sold in this community. But I do think that this led to some aha moments in terms of } \\
\text { communication." }\end{array}$ \\
\hline $\begin{array}{l}\text { Coalition: } \\
\text { Implementation } \\
\text { Climate (all) }\end{array}$ & $\begin{array}{l}\text { Reduction in } \\
\text { readmission } \\
\text { rates }\end{array}$ & $\begin{array}{l}\text { "At the bare minimum, they were residing in hospitals where every day they had readmission discussions going on. So } \\
\text { it became a real hospital system level priority. I've mentioned it already, the hospital C Suites being very plugged into } \\
\text { the C Suite visits and sharing data and talking to them about what is working and what is not working. And engaging } \\
\text { the post-acute providers. We had such a robust post-acute provider coalitions going, where a hospital would meet with } \\
\text { seven or eight of their preferred provider nursing homes and home health agencies, we were always a part of those } \\
\text { meetings. We were often the facilitators for those meetings, because they would get sometimes a little bit ugly, where } \\
\text { the hospitals would just almost thrash about the nursing homes, which never seems to be a great motivation for } \\
\text { getting people to work with you on things. And so we would often serve as the mediator, or as the facilitator of that } \\
\text { meeting to talk through different issues. That was really important while they learned how to talk to each other." }\end{array}$ \\
\hline $\begin{array}{l}\text { Coalition: } \\
\text { Implementation } \\
\text { Climate (all) }\end{array}$ & $\begin{array}{l}\text { Increase in } \\
\text { readmission } \\
\text { rates }\end{array}$ & $\begin{array}{l}\text { "It was kind of what we see in a lot of communities that was one more thing that somebody was asking them to do. } \\
\text { And so, that may have added to the lack of enthusiasm. I mean it wasn't that they didn't believe that it was something } \\
\text { that was needed. But there just were competing priorities, I believe." }\end{array}$ \\
\hline $\begin{array}{l}\text { Coalition: } \\
\text { Implementation } \\
\text { Climate (all) }\end{array}$ & $\begin{array}{l}\text { Minimal } \\
\text { change in } \\
\text { readmission } \\
\text { rates }\end{array}$ & $\begin{array}{l}\text { "I think just the collaborative effort of the community in general compared to some of the other coalitions we've seen, } \\
\text { this one is consistently well-attended. It's the right people in the room that are really working with patients and doing } \\
\text { the readmissions work. So I think that's probably contributed to the success is that it's the same consistent people that } \\
\text { have been coming together, monthly, looking at data, so it's data-driven and it's been a long time. It's an older coalition, } \\
\text { so they've been meeting consistently and I think just kind of know how to work well together...I mean, I definitely think } \\
\text { it's had an impact on the readmission rates just because they're able to talk freely and as I said, they're comfortable } \\
\text { sharing their data because I think, they trust each other and they trust that the goals are all aligned with what their } \\
\text { trying to do. I just think the relationships have a big impact on the overall success of the readmission work within the } \\
\text { coalition. And again, just having the right people in the room. We've seen other coalitions where it tends to start being } \\
\text { geared towards more marketing folks attending. But these are really case managers, people that are directly working } \\
\text { with the beneficiaries." }\end{array}$ \\
\hline $\begin{array}{l}\text { Outer Setting: } \\
\text { Population } \\
\text { Characteristics }\end{array}$ & $\begin{array}{l}\text { Reduction in } \\
\text { readmission } \\
\text { rates }\end{array}$ & $\begin{array}{l}\text { "And also go back and start looking at system-level changes that needed to occur, if that makes sense. When you start } \\
\text { looking at social determinants of health, probably one of the biggest things we learned around this project was the } \\
\text { need around affordable housing, food, and transportation, things that came out in the root cause analysis that we do- } \\
\text { the coalition. But it was particularly highlighted around this set of patients. The reason, in part, that they were re- } \\
\text { admitting was because of these social determinants of health. Then we could go back and have system-level change } \\
\text { or system-level discussions within the coalition and whether or not they wanted to take anything on." }\end{array}$ \\
\hline $\begin{array}{l}\text { Outer Setting: } \\
\text { Population } \\
\text { Characteristics }\end{array}$ & $\begin{array}{l}\text { Increase in } \\
\text { readmission } \\
\text { rates }\end{array}$ & $\begin{array}{l}\text { "What we know about patients in this community - there are [certain patients] that go to the ER and end up being } \\
\text { admitted. There's data out there that you can look at... If these patients are showing up to the ER [and] they have } \\
\text { multiple issues, and they're coming to the ER late, they're being admitted." }\end{array}$ \\
\hline $\begin{array}{l}\text { Outer Setting: } \\
\text { Population } \\
\text { characteristics }\end{array}$ & $\begin{array}{l}\text { Minimal } \\
\text { change in } \\
\text { readmission } \\
\text { rates }\end{array}$ & $\begin{array}{l}\text { "I think one of the struggles has been, and I don't think this is just a struggle for [this community], to get the basics } \\
\text { done well. A great example would be a person comes in and you identify who they are by their name and their } \\
\text { birthday. That would be an easy two-factor identification of someone, but I don't see that we have consistency around } \\
\text { some of those basic things that result in care getting delivered where it needs to be, when it needs to be, how it needs } \\
\text { to be for that individual. I think that lack of coming at the problem at the community is problematic. We have a whole } \\
\text { lot of special-ness, where everybody thinks that their patient population is special, and that they're special, and their } \\
\text { providers are special. And the reality is there's a whole lot of-common problems are common-I guess is the best way } \\
\text { to say it." }\end{array}$ \\
\hline
\end{tabular}

\section{Discussion}

The CFIR provided a useful taxonomy for describing and capturing meaningful aspects of implementation in this complex, coalition-facilitated, multistakeholder initiative to reduce readmissions incidence. The conceptual domains and constructs of the CFIR were readily accepted as natural categories, and generally intuitive, to QIN-QIO staff who provided technical assistance through stakeholder coalitions, and domains often overlapped with elements already being reported by QIN-QIOs. Our interviews, guided by these domains and constructs, were frequently perceived as helpful to interviewees in organizing program lessons, and cataloguing important aspects of community efforts to implement interventions:

And it's really made me think about the consistency, continuity of interventions, and how we easily were pulled off into these different directions. It would be interesting to see how this particular intervention and this particular community fit in the framework that you're researching for this project. It's really helped us 
to think about things...

The fields of quality improvement and implementation science are conceptually distinct but with intersecting goals. Quality improvement has been characterized as beginning with an identified performance gap in a specific healthcare system, then using small tests of change to drive development of intervention and implementation strategies simultaneously. Implementation science typically begins with an underused evidence-based practice, and studies and remedies organizational, contextual and other factors that impede the practice's implementation (26). In reality, the distinction is blurry as many quality improvement initiatives promote established interventions, and most implementation efforts involve significant, ongoing adaptation (27). Greater integration of formal implementation science tools into national quality improvement initiatives might advance both fields: quality improvement through standardizing implementation elements to support rigorous monitoring and evaluation designs; and implementation science through dramatically increasing the number of implementation examples available to study. Hundreds of implementation tests generated through national quality improvement initiatives, coded to an implementation taxonomy, could be used to test hypotheses (28) and generate distinct explanatory and predictive models.

Indeed, in 2012, a conference on Advancing Methods for Healthcare Quality Improvement Research (29) was convened to synthesize quality improvement research methods and generate ways to build on its strengths in the future. It was noted that for quality improvement efforts to make significant contributions to the health care services research literature, it would need to reach a "higher level of validity and value." In other words, methods need the rigor of current medical and economic research efforts. However, quality improvement efforts are not well suited to controlled trials; they take place in uncontrolled settings and contexts and are met with different levels of investment and commitment from organizational leadership and front line staff. As noted by Toulany and colleagues, what is needed are research methods that allow for and understand the impact of this variation, with more defined and detailed descriptions of local contexts, to learn lessons from both high and low performing teams rather than controlling variable elements (30). The CFIR provides a useful and applicable framework by which to identify contextual features of a given setting and understand which ones matter and how.

If applied to national quality improvement campaigns it would result in a large database of standardized elements and outcomes for testing complex intervention and implementation relationships, even with a high degree of variation among individual projects.

Other quality initiatives have found the CFIR useful for informing rapid-cycle approaches to improving implementation (31). The CFIR aggregates common elements from many theories and frameworks and is therefore consistent with most conceptual models in dissemination and implementation research (16). It has sufficient detail to capture a comprehensive spectrum of pertinent information and can be easily tailored to relevant aspects of a given implementation effort. We added three new codes for evidence strength \& quality, seven to the Outer Setting domain, and 17 existing CFIR constructs to a new Coalition Setting domain to capture elements important to this community-based initiative. We believe our set of domains and constructs aligned to the CFIR is a promising start to a standardized tool suitable for guiding and assessing future coalition-facilitated, community-based quality improvement strategies. In addition, other quality improvement organizations have found that using CFIR may be useful to inform rapid-cycle approaches to improving implementation.

As this initiative aimed to foster change that would impact the whole Medicare population of the community, QIN-QIO staff had detailed and nuanced insights into many aspects of the community environment. As a result, they provided much information about outer setting contextual features, and we refined these codes to ensure key details were accounted for. This was particularly evident with the new code, healthcare market characteristics, which was rated as influential to implementation in every community interviewed and demonstrated a clear relationship between the nature of that influence (positive or negative) and performance on RIR. Interviewees frequently referenced the presence of other initiatives (eg. an Accountable Care Organization) or other provider arrangements within the community as being influential on how providers interacted with each other, and their subsequent capacity to prioritize interdependent improvement activity or resources for care coordination interventions. For example, many answers about what influenced readmission rates over the course of the project contained descriptive information such as "there are three separate hospital systems in this community" or "all our hospitals are for profit". One helpful addition to the outer setting domain would be a distinction between local outer setting influences from non-local outer setting characteristics, as suggested by the Promoting Action on Research Implementation (PARiHS) framework (32). For example, general awareness of readmissions payment penalties is probably less influential to a community coalition-led effort than having one or more coalition participants either receiving or being at imminent risk of receiving a penalty. Future efforts should seek to catalogue the types of healthcare market characteristics that seem important in greater detail and test their associations with both successful implementation and change in readmission rates. Constructs shown to influence implementation and/or outcomes could then be organized into existing outer setting constructs or appended to a framework for describing community-based implementation efforts.

Our decision to create a new coalition domain acknowledges the interface where the QIN-QIOs, who were our data source, were most knowledgeable. In a single setting implementation, the inner setting is where the actors make change, and the coalition is the inner setting where QIN-QIOs were making change. Results of coding existing CFIR constructs to the coalition domain reflects this, as the majority of constructs we coded as coalition constructs are defined by the CFIR as inner setting constructs. Because many QIN-QIOs also had meaningful insights into provider settings where patients were directly impacted by implementation efforts, we retained the inner setting domain as a separate contextual level.

The CFIR is an evaluation framework designed to comprehensively assess factors relevant to successful program implementation in a specific inner setting, but it was not designed to explain nor evaluate a dynamic program that incorporates many settings, participants, and interventions. Nevertheless, we found consistent practices that suggest future directions should focus on standardizing implementation strategies, data collection, and evaluation approaches for similarly complex initiatives. We found that all interviewed QIN-QIOs formed and supported coalitions; all supplied data and analyzed root causes of readmissions; and most communities had providers that successfully implemented interventions. Our results suggest that coalitions may be helpful for driving change among a group of providers by offering a networking and communication platform, and by fostering an implementation climate that enhances a sense of priority and urgency for solving the problem of readmissions. The subconstructs of readiness for implementation, leadership engagement and available resources are likely to matter most at the implementation point of action, that is, within the provider organizations carrying forward those activities.

Page 16/19 
Similarly, communities that more effectively reduced readmissions may have been better at engaging the right people in the right roles to succeed in implementing appropriate interventions. These communities also seem to have had more robust planning and execution of planned interventions.

\section{Limitations}

Our data is qualitative and obtained from interviews with QIN-QIO staff reflecting a single perspective within the communities from which we sought to learn about parameters of complicated interventions, relationships, and contexts. We did not interview provider staff. The information obtained and constructs identified were therefore biased towards what an external technical assistance agency could reasonably know about providers, their activities, and the attitudes and actions that they brought to the work. QIN-QIO interviewees may have wanted to present their communities and their work positively, leading to overestimation or underestimation of the influence of any given construct. Quarterly trend data of readmission rates and RIR was openly shared by QIN-QIOs throughout the program, so both interviewers and interviewees knew the community's performance during interviews, transcription, coding and rating. Our ratings, rationales, and community summaries were not verified for accuracy by interviewees. This project aimed to create assessment tools for future similar efforts, therefore, our results were obtained after the project had ended. Additionally, contracts stipulated that each QIN-QIO work with enough communities to impact $60 \%$ of the Medicare FFS beneficiaries in their states. Inevitably we received more information about low performing communities because QIN-QIO staff were likely to have been more engaged in those communities, and furthermore required by the funding agency (CMS) to provide more detailed and frequent assessments of these communities. Our methods may have therefore systematically underestimated either positive or negative influences among high performing communities. Although these limitations may have significantly biased inferences around the strength of association between any construct and either implementation or readmissions outcomes, they are unlikely to have influenced the degree to which the CFIR served as a taxonomy.

\section{Conclusions}

The CFIR could form the backbone of a common taxonomy for complex, multi-stakeholder community-based care coordination efforts, as shown by our data and others' experiences (31). Establishing that a taxonomy would have the potential to accelerate detection and replication of best practices by allowing aggregation of insights from communities with a wide range of context and performance, as well as variations in improvement strategies. Future efforts should aim to apply our modified constructs to a larger group of community-based improvement efforts and thereby to validate or further adapt them. Once a taxonomy is established, formal implementation research techniques should test the impact of identified constructs and the interaction of constructs in explanatory and predictive implementation models.

\section{Abbreviations}

\begin{tabular}{ll} 
ACO: & Accountable Care Organization \\
\hline CFIR: & Consolidated Framework for Implementation Research \\
\hline CMS: & Centers for Medicare \& Medicaid Services \\
\hline EPIS: & Exploration, Preparation, Implementation, Sustainment \\
\hline FFS: & Fee-for-Service \\
\hline NQS: & National Quality Strategy \\
\hline PARiHS: & Promoting Action on Research Implementation \\
\hline QIN-QIO: & Quality Innovation Network-Quality Improvement Organizations \\
\hline RCA: & Root Cause Analysis \\
\hline RIR: & Relative Improvement Rate \\
\hline
\end{tabular}

\section{Declarations}

\section{Ethics approval and consent to participate}

This research was exempted from review by the Institutional Review Board of the University of Colorado Institutional Review Board (COMIRB submission \#NHSR001-2). Participation was voluntary, and all interviewees verbally consented to participate prior to the beginning of each interview.

\section{Consent for publication}

Not applicable

\section{Availability of data and materials}

All files supporting the conclusions of this article are included within the article or in the Additional Files.

\section{Competing interests}

$\mathrm{JB}, \mathrm{BG}, \mathrm{AB}, \mathrm{LM}, \mathrm{KW}$ AH, JH and $\mathrm{CG}$ declare that they have no competing interests. 


\section{Funding}

JB, BG, AB, LM, and KW performed this work as a part of the National Coordinating Center contract to support the QIN-QIO 11th Statement of Work (HHSM500-2014-QINNCC). Christina Goatee contributed to this paper as part of her role as an employee of the Centers for Medicare \& Medicaid Services. AH and JH received grant funding from Telligen to provide expertise to the framing and conduct of this research, and assistance in preparing this manuscript.

\section{Authors' contributions}

All authors made substantial contributions to the conception and design or analysis and interpretation of the data and drafting of the article or critical revision for important intellectual content. JB, BG, AB, LM, KW, CG, AH and JH designed the study; JB, BG, AB, LM and KW performed all interviews and scored all qualitative data; $A B$ and $B G$ performed all analyses; $\mathrm{JB}, \mathrm{BG}, \mathrm{AB}$ and $\mathrm{LM}$ wrote the manuscript. $\mathrm{GC}, \mathrm{AH}$ and $\mathrm{JH}$ provided substantial editing and contributed to the writing of sections of the manuscript. JB, BG, AB, LM, KW CG, AH and JH reviewed and edited the final manuscript, tables, figures, additional files and appendices.

\section{Acknowledgements}

We would like to acknowledge the QIO leaders who gave their time to participate in interviews, their thoughtfulness in responding to interviewers, and the diligence with which they approached the task of reducing community readmission rates. We are grateful to Alliant Quality, Comagine Health, Great Plains Quality Innovation Network, Health Services Advisory Group (HSAG), Healthcentric Advisors, Lake Superior Quality Innovation Network, Mountain-Pacific Quality Health, Qsource, Quality Insights, Telligen, and TMF Health Quality Institute for making this paper possible. We also thank Laura Damschoder and her team at the Veteran Administration's Ann Arbor Center for Clinical Management Research, Ann Arbor, MI, USA, for their generosity in providing guidance to this project; and Joanne Lynne, MD, MA, MS, for being the visionary force behind community-based, coalition-led improvement campaigns to reduce the cycle of repeated hospitalizations for vulnerable elderly people.

\section{References}

1. About the National Quality Strategy | Agency for Healthcare Research \& Quality [Internet]. 2017 [cited 2019 Aug 28]. Available from: https://www.ahrq.gov/workingforquality/about/index.html

2. Mitchell SE, Laurens V, Weigel GM, Hirschman KB, Scott AM, Nguyen HQ, et al. Care Transitions From Patient and Caregiver Perspectives. Ann Fam Med. 2018;16(3):225-31.

3. Jencks SF, Williams MV, Coleman EA. Rehospitalizations among patients in the Medicare fee-for-service program. N Engl J Med. 2009 Apr 2;360(14):1418-28.

4. Burton R. Health Policy Brief: Improving Care Transitions [Internet]. Health Policy Brief. 2012 [cited 2019 Sep 4]. Available from: https://www.healthaffairs.org/do/10.1377/hpb20120913.327236/full/

5. Coleman EA. Falling through the cracks: challenges and opportunities for improving transitional care for persons with continuous complex care needs. J Am Geriatr Soc. 2003 Apr;51(4):549-55.

6. Li J, Brock J, Jack B, Mittman B, Naylor M, Sorra J, et al. Project ACHIEVE - using implementation research to guide the evaluation of transitional care effectiveness. BMC Health Serv Res. 2016 Feb 19;16:70.

7. Scott AM, Li J, Oyewole-Eletu S, Nguyen HQ, Gass B, Hirschman KB, et al. Understanding Facilitators and Barriers to Care Transitions: Insights from Project ACHIEVE Site Visits. Jt Comm J Qual Patient Saf. 2017;43(9):433-47.

8. Anthony D, Chetty VK, Kartha A, McKenna K, DePaoli MR, Jack B. Re-engineering the Hospital Discharge: An Example of a Multifaceted Process Evaluation. In: Henriksen K, Battles JB, Marks ES, Lewin DI, editors. Advances in Patient Safety: From Research to Implementation (Volume 2: Concepts and Methodology) [Internet]. Rockville (MD): Agency for Healthcare Research and Quality (US); 2005 [cited 2019 Aug 28]. (Advances in Patient Safety). Available from: http://www.ncbi.nlm.nih.gov/books/NBK20484/

9. Snow V, Beck D, Budnitz T, Miller DC, Potter J, Wears RL, et al. Transitions of Care Consensus Policy Statement American College of Physicians-Society of General Internal Medicine-Society of Hospital Medicine-American Geriatrics Society-American College of Emergency Physicians-Society of Academic Emergency Medicine. J Gen Intern Med. 2009 Aug;24(8):971-6.

10. Naylor MD, Shaid EC, Carpenter D, Gass B, Levine C, Li J, et al. Components of Comprehensive and Effective Transitional Care. J Am Geriatr Soc. 2017 Jun;65(6):1119-25.

11. Centers for Medicare \& Medicaid Services. Current Work [Internet]. 2019 [cited 2019 Aug 28]. Available from: https://www.cms.gov/Medicare/QualityInitiatives-Patient-Assessment-Instruments/QualitylmprovementOrgs/Current.html

12. Centers for Medicare \& Medicaid Services. Past Work [Internet]. 2016 [cited 2019 Aug 28]. Available from: https://www.cms.gov/Medicare/QualityInitiatives-Patient-Assessment-Instruments/QualityImprovementOrgs/Past.html

13. Quality Improvement Organizations | Sharing Knowledge. Improving Health Care. [Internet]. Quality Improvement Organizations. [cited 2019 Aug 28]. Available from: https://qioprogram.org/home

14. 2011 Report to Congress: National Strategy for Quality Improvement in Health Care [Internet]. 2016 [cited 2019 Aug 28]. Available from: https://www.ahrq.gov/workingforquality/reports/2011-annual-report.html

15. Brock J, Mitchell J, Irby K, Stevens B, Archibald T, Goroski A, et al. Association between quality improvement for care transitions in communities and rehospitalizations among Medicare beneficiaries. JAMA. 2013 Jan 23;309(4):381-91. 
16. Damschroder LJ, Aron DC, Keith RE, Kirsh SR, Alexander JA, Lowery JC. Fostering implementation of health services research findings into practice: a consolidated framework for advancing implementation science. Implement Sci IS. 2009 Aug 7;4:50.

17. The Consolidated Framework for Implementation Research [Internet]. The Consolidated Framework for Implementation Research. [cited 2019 Aug 28]. Available from: https://cfirguide.org/

18. Damschroder LJ, Lowery JC. Evaluation of a large-scale weight management program using the consolidated framework for implementation research (CFIR). Implement Sci IS. 2013 May 10;8:51.

19. Hill JN, Locatelli SM, Bokhour BG, Fix GM, Solomon J, Mueller N, et al. Evaluating broad-scale system change using the Consolidated Framework for Implementation Research: challenges and strategies to overcome them. BMC Res Notes. 2018 Aug 4;11(1):560.

20. Weir NM, Newham R, Dunlop E, Bennie M. Factors influencing national implementation of innovations within community pharmacy: a systematic review applying the Consolidated Framework for Implementation Research. Implement Sci IS. 2019 04;14(1):21.

21. Pawson R. The science of evaluation: a realist manifesto. Sage; 2013.

22. Brehaut JC, Eva KW. Building theories of knowledge translation interventions: Use the entire menu of constructs. Implement Sci IS. 2012 Nov $22 ; 7: 114$.

23. Kind AJH, Buckingham WR. Making Neighborhood-Disadvantage Metrics Accessible - The Neighborhood Atlas. N Engl J Med. 2018 Jun 28;378(26):2456-8.

24. McHugh M, Harvey JB, Hamil J, Scanlon DP. Improving care delivery at the community level: an examination of the AF4Q legacy. Am J Manag Care. 2016 Aug;22(12 Suppl):s393-402.

25. Tools and Templates [Internet]. The Consolidated Framework for Implementation Research. 2016 [cited 2019 Sep 9]. Available from: https://cfirguide.org/wp-content/uploads/2019/08/cfircodebooktemplate10-27-2014.docx

26. Bauer MS, Damschroder L, Hagedorn H, Smith J, Kilbourne AM. An introduction to implementation science for the non-specialist. BMC Psychol. 2015 Sep 16;3:32.

27. Chambers DA, Norton WE. The Adaptome: Advancing the Science of Intervention Adaptation. Am J Prev Med. 2016;51(4 Suppl 2):S124-131.

28. Ilott I, Gerrish K, Booth A, Field B. Testing the Consolidated Framework for Implementation Research on health care innovations from South Yorkshire. J Eval Clin Pract. 2013 Oct;19(5):915-24.

29. Speroff T, Miles PV, Dougherty D, Mittman BS, Splaine ME. Introduction to the Academy for Healthcare Improvement conference on advancing the methods for healthcare quality improvement research. Implement Sci. 2013 Apr 19;8(1):I1.

30. Toulany A, McQuillan R, Thull-Freedman JD, Margolis PA. Quasi-Experimental designs for quality improvement research. Implement Sci. 2013 Apr 19;8(1):S3.

31. Keith RE, Crosson JC, O'Malley AS, Cromp D, Taylor EF. Using the Consolidated Framework for Implementation Research (CFIR) to produce actionable findings: a rapid-cycle evaluation approach to improving implementation. Implement Sci IS. 2017 10;12(1):15.

32. Rycroft-Malone J, Seers K, Chandler J, Hawkes CA, Crichton N, Allen C, et al. The role of evidence, context, and facilitation in an implementation trial: implications for the development of the PARIHS framework. Implement Sci IS. 2013 Mar 9;8:28.

\section{Supplementary Files}

This is a list of supplementary files associated with this preprint. Click to download.

- AdditionalfileXXISSMCOREQChecklistCFIR20200814.pdf

- Additionalfile4CommunityHeatmapFNL.xIsx

- Additionalfile3ModifiedCFIRCodebookFNL.docx

- Additionalfile2InterviewGuideFNL.docx

- Additionalfile1CFIRRespondentAssessmentFNL.pdf 